\title{
Characterization Studies of 1-(4-Cyano-2-oxo-1,2-dihydro-1-pyridyl)-3-(4-cyano- 1,2-dihydro-1-pyridyl)propane Formed from the Reaction of Hydroxide Ion with 1,3-Bis-(4-cyano pyridinium)propane
}

\author{
Simone Fiori, ${ }^{a}$ Ivânia T. A. Schuquel, ${ }^{a}$ Idélcio N. da Silva, ${ }^{b}$ Mário J. Politi, ${ }^{c}$ \\ Luiz H. Catalani, ${ }^{c}$ Hernan Chaimovich, ${ }^{c}$ Emerson Meyer ${ }^{a}$ and Noboru Hioka*,a \\ ${ }^{a}$ Departamento de Química, Universidade Estadual de Maringá, 87020-900 Maringá-PR, Brazil \\ ${ }^{b}$ Fundação Educacional do Município de Assis, 19807-634 Assis-SP, Brazil \\ 'Instituto de Química, Universidade de São Paulo, 05508-000 São Paulo-SP, Brazil
}

\begin{abstract}
A reação em meio aquoso alcalino do dibrometo de 1,3-bis(4-cianopiridinium)propano, um composto constituído por dois anéis piridínicos conectados por uma ponte metilênica de três carbonos, gerou um novo composto, o 1-(4-ciano-2-oxo-1,2-diidro-1-piridil)-3-(4-ciano-1,2diidro-1-piridil)propano. O resultado da reação é atribuído à proximidade do íon $\mathrm{OH}^{-}$, encapsulado entre os dois anéis piridínicos, fato este observado apenas em derivados bis-piridínicos conectados por pontes metilênicas de curta extensão, onde imperam efeitos de carga aliados à conformação.
\end{abstract}

The aqueous alkaline reaction of 1,3-bis(4-cyanopyridinium)propane dibromide, a reactant constituted of two pyridinium rings linked by a three-methylene bridge, generates a novel compound, 1-(4-cyano-2-oxo-1,2-dihydro-1-pyridyl)-3-(4-cyano-1,2-dihydro-1-pyridyl)propane. The reaction pathway is attributed to the proximity of the $\mathrm{OH}^{-}$ion inserted between two pyridinium moieties, which occurs only in bis(pyridinium) derivatives connected by short methylene spacers, where charge-conformational effects are important.

Keywords: cyanopyridinium, alkaline reaction, 1-(4-cyano-2-oxo-1,2-dihydro-1-pyridyl)-3(4-cyano-1,2-dihydro-1-pyridyl)propane, charge-conformational effects

\section{Introduction}

$\mathrm{N}$-alkylpyridinium ions undergo a variety of chemical reactions, such as nucleophilic substitutions and photochemical and electrochemical redox processes. ${ }^{1,2}$ The structure and facile synthesis of substituted $\mathrm{N}$-alkylpyridinium ions make these compounds of particular interest as models for the study of a range of different problems, including micellar effects on chemical reactivity and biological redox mechanisms. ${ }^{3,4}$ We have used $\mathrm{N}$-alkyl-4-cyano-pyridinium ions (RCP) to probe several properties of self-assembled aggregates constituted by surfactants and other amphiphiles. ${ }^{4-7} \mathrm{RCP}$ compounds usually undergo attack by $\mathrm{OH}^{-}$ion at two different sites, carbon 4 of the pyridinium ring (ipso attack) and the $-\mathrm{CN}$ group, yielding the respective pyridone $(\mathbf{P})$ and carboxamidopyridinium (A), as illustrated in Scheme $1 .{ }^{1}$

*e-mail: nhioka@uem.br

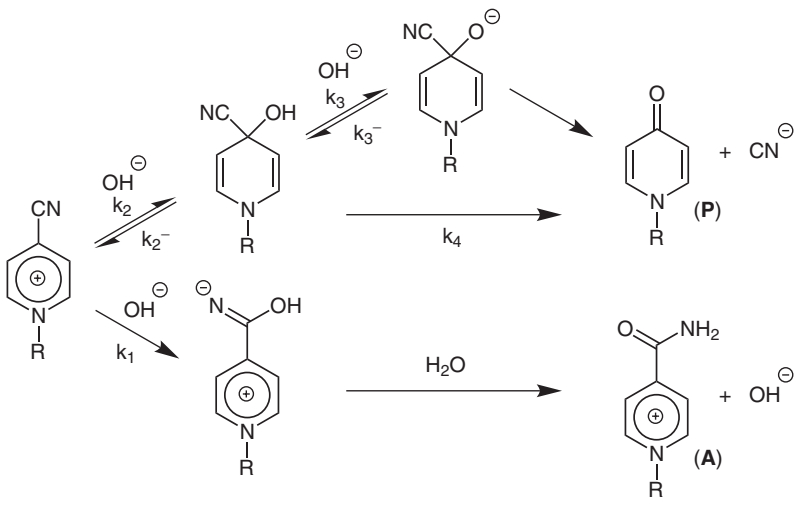

Scheme 1. Reaction pathways of RCP compounds with $\mathrm{OH}^{-}$ion.

The reaction rate constants and the product ratios (P/A) of $\mathrm{RCP}$ derivatives are $\mathrm{pH}$ - and dielectric constant-dependent and these features can be used as tools to investigate several reactional details. ${ }^{4-6}$ For example, the reaction of micelle-incorporated RCP with $\mathrm{OH}^{-}$ion yields only $\mathbf{P} .{ }^{4}$ The determination of the effect of micelles on the reaction 
rate and product composition was therefore used to study the interfacial region in ionic and zwitterionic micelles. ${ }^{6}$

The RCP analog $N$-hexadecyl-4-cyanopyridinium (HCP) shows a reactivity pattern that is completely different from that of $N$-methyl-4-cyanopyridinium (MCP); HCP presents surfactant characteristics, while MCP behaves as a simple pyridinium salt. ${ }^{5}$ The HCP molecule has been demonstrated to self-associate even below its critical micelle concentration (CMC). This premicellar aggregation was demonstrated on the basis of concentration-dependent rate constant and product composition differences in alkaline hydrolysis reaction as a function of the HCP concentration. ${ }^{5}$

The increased reactivity of the premicellar aggregates (as dimers) formed by HCP led us to synthesize a series of bis(substituted-pyridinium) salts with the two pyridinium rings covalently linked by methylene spacers in order to investigate their kinetic behavior and product composition against distinct nucleophiles. ${ }^{8,9}$ For example, the reaction of 1, $\omega$-bis(2-bromopyridinium)alkanes with hydroxide ${ }^{8}$ and azide $^{9}$ was investigated in order to analyze the charge-conformational effects on their reactivity.

Our work on the alkaline hydrolysis of 1, $\omega$-bis (4-cyanopyridinium)alkanes (Scheme 2) revealed a rather interesting result for the propyl-bridged derivative (1).

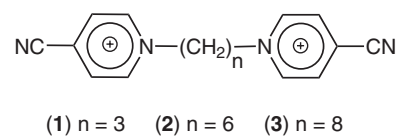

Scheme 2. 1, $\omega$-bis(4-cyanopyridinium)alkanes reactants.

Even under moderate $\mathrm{OH}^{-}$concentration, salt $\mathbf{1}$ yields a novel additional product besides the expected $\mathbf{P}$ and $\mathbf{A}$. The aim of the present work is to characterize this new compound.

\section{Results and Discussion}

UV spectra of RCP and the products of its alkaline hydrolysis show characteristic electronic transitions with absorption maxima centered at $278 \mathrm{~nm}$ and at $262 \mathrm{~nm}$, respectively. ${ }^{1}$ Spectral changes observed upon the addition of compounds $\mathbf{2}$ and $\mathbf{3}$ (Scheme 2) to an alkaline aqueous solution ( $\mathrm{pH} 9.0$ to 13.8 ) were very similar to those obtained with $\mathrm{RCP},{ }^{7}$ indicating that the reaction products are constituted by pyridone and carboxamidopyridinium moieties (Scheme 1), both absorbing at the $262 \mathrm{~nm}$ region.

The UV spectra of the alkaline hydrolysis products of 1,3-bis-(4-cyano pyridinium)propane dibromide (1) at $\mathrm{pH}$ values below 11.5 were similar to those obtained from 2 and 3. However, at $\mathrm{pH}$ values higher than 11.5 , the spectrum of products from 1 exhibits an additional band at $336 \mathrm{~nm}$ beside the usual band at $262 \mathrm{~nm}$ (related to the $\mathbf{P}$ and $\mathbf{A}$ units) (Figure 1).

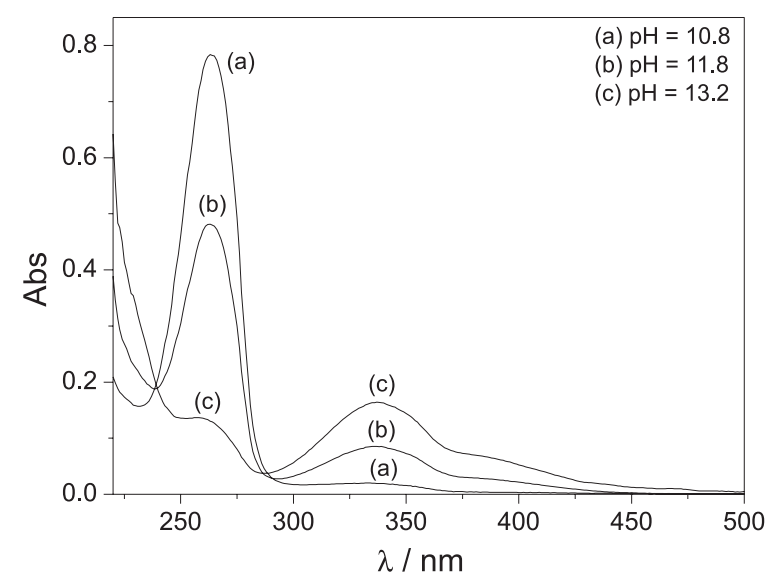

Figure 1. UV-Vis spectra of the products obtained from the alkaline reaction of $\mathbf{1},\left(2.9 \times 10^{-5} \mathrm{~mol} \mathrm{~L}^{-1}\right)$ conducted at (a) $\mathrm{pH} 10.8$, (b) $\mathrm{pH} 11.8$, and (c) $\mathrm{pH}$ 13.2.

Figure 1 shows that as the $\mathrm{OH}^{-}$concentration increases, the band at $336 \mathrm{~nm}$ also increases. Therefore, a highly alkaline concentration favors the formation of the additional product from compound $\mathbf{1}$.

A scaled-up reaction of $\mathbf{1}$ with aqueous $\mathrm{NaOH}$ at room temperature led immediately to a brown-yellowish solution and a brown precipitate. The solid product, which was responsible for the absorption band at $336 \mathrm{~nm}$, was filtered off. This product, both in solid state and in solution, promptly changed to a dark color, exhibiting high susceptibility to oxidation.

Initial attempts to isolate the solid product in pure state by column chromatography and rotating disk TLC (chromatroton) failed due to the fast decomposition of the material at room temperature. Instead of filtration, an alternative two-phase transfer isolation technique at low temperature was performed (see Experimental section).

For NMR analysis, a $\mathrm{D}_{2} \mathrm{O}$ solution of $\mathbf{1}$ was reacted with a heterogeneous mixture of $\mathrm{NaOD} / \mathrm{D}_{2} \mathrm{O} / \mathrm{CDCl}_{3}$ at low temperature. In this strategy, the additional product was transferred to the organic phase and properly analyzed as soon as it was formed.

${ }^{1} \mathrm{H}$ and ${ }^{13} \mathrm{C}$ NMR, MS, FT-IR, and elemental analyses indicate that the product has the structure shown in Scheme 3.

The mass spectrum shows a molecular ion peak at 266, which is in agreement with the elemental analysis $\left(\mathrm{C}_{15} \mathrm{H}_{14} \mathrm{~N}_{4} \mathrm{O}\right)$ and in full accordance with the proposed structure 4. The NMR data are summarized in Table 1. 


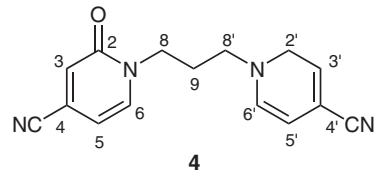

Scheme 3. Proposed product.

Table 1. NMR data for the additional compound obtained from 1 in $\mathrm{D}_{2} \mathrm{O}$ ([NaOD] ca. $1.8 \mathrm{~mol} \mathrm{~L}^{-1}$ ), taken at $-20^{\circ} \mathrm{C}$ in $\mathrm{CDCl}_{3} / \mathrm{TMS}$

\begin{tabular}{lcc}
\hline Position & $\delta^{13} \mathrm{C}^{\mathrm{a}}, \mathrm{DEPT}$ & $\delta{ }^{1} \mathrm{H}^{\mathrm{b}}\left(\mathrm{mult} ; J^{\mathrm{c}}\right)$ \\
\hline 2 & $160.6, \mathrm{C}$ & - \\
3 & $126.9, \mathrm{CH}$ & $6.94(\mathrm{dd} ; 1.8 ; 0.9)$ \\
4 & $123.9, \mathrm{C}$ & - \\
5 & $105.8, \mathrm{CH}$ & $6.37(\mathrm{dd} ; 6.9 ; 1.8)$ \\
6 & $140.8, \mathrm{CH}$ & $7.44(\mathrm{dd} ; 6.9 ; 0.9)$ \\
7 & $118.2, \mathrm{C}$ & - \\
8 & $48.4, \mathrm{CH}_{2}$ & $4.00(\mathrm{t} ; 6.6)$ \\
9 & $25.7, \mathrm{CH}_{2}$ & $1.99(\mathrm{quint} ; 6.6)$ \\
8 & $3.00(\mathrm{t} ; 6.6)$ \\
2 & $52.0, \mathrm{CH}_{2}$ & $4.01(\mathrm{~d} ; 4.8)$ \\
3 & $46.8, \mathrm{CH}_{2}$ & - \\
4 & $122.7, \mathrm{CH}^{\prime}$ & $5.74(\mathrm{tdd} ; 4.8 ; 1.8 ; 0.9)$ \\
5 & $112.3, \mathrm{C}$ & $4.71(\mathrm{dd} ; 7.2 ; 1.8)$ \\
6 & $92.8, \mathrm{CH}$ & $6.10(\mathrm{dd} ; 7.2 ; 0.9)$ \\
7 & $140.3, \mathrm{CH}$ & - \\
\hline
\end{tabular}

${ }^{2} 75.457 \mathrm{MHz}$ for ${ }^{13} \mathrm{C} ;{ }^{b} 300.059 \mathrm{MHz}$ for ${ }^{1} \mathrm{H} ;{ }^{\mathrm{c}} \mathrm{J}$ in $\mathrm{Hz}$.

As can be seen, the ${ }^{13} \mathrm{C}$ NMR spectrum (Table 1) shows 15 signals that point to an asymmetrical structure, with two different pyridine-like rings. The DEPT 90 and 135 analyses confirmed the presence of 4 signals relative to methylenic carbons $\left(\mathrm{CH}_{2}\right)$, six signals of methynic carbons $(\mathrm{CH})$, and five non hydrogen-bonded carbons $(\mathrm{C})$.

Regarding the 4-cyano-2-pyridone moiety, the signal at $160.6 \mathrm{ppm}$ is related to the carbonyl group (C2), the signal at $118.2 \mathrm{ppm}$ is associated with the carbon of the cyano group (C7), and the signal at $123.9 \mathrm{ppm}$ corresponds to the carbon connected to the cyano group (C4). These results were confirmed by FT-IR analysis which spectrum exhibited the $1665 \mathrm{~cm}^{-1}$ peak that corresponds to the carbonyl and the axial deformation band of the (two) $\mathrm{CN}$ groups at 2216 and $2234 \mathrm{~cm}^{-1}$.

The ${ }^{1} \mathrm{H}$ NMR data are also consistent with the proposed structure. The ${ }^{1} \mathrm{H}$ NMR and ${ }^{1} \mathrm{H}-{ }^{1} \mathrm{H}$ COSY spectra show two doublets of doublets from ortho-coupled hydrogens at $6.37 \mathrm{ppm}$ and $7.44 \mathrm{ppm}$, and another mutually coupled doublet of doublets at $6.94 \mathrm{ppm}$, attributed to the hydrogen connected to $\mathrm{C} 3 .{ }^{1} \mathrm{H}$ and ${ }^{13} \mathrm{C}$ analyses are in agreement with those obtained from a similar known compound in the literature (4-cyano-2-pyridone)..$^{10}$
The methylenic carbons at $48.4 \mathrm{ppm}(\mathrm{C} 8)$ and $52.0 \mathrm{ppm}$ (C8') are related to carbons of the chain bridge. The ${ }^{1} \mathrm{H}$ NMR spectrum has two triplets centered at $4.00 \mathrm{ppm}$ and $3.00 \mathrm{ppm}$, which, according to HMQC analysis, are attached to carbons C8 and C8', respectively. Finally, C9 is observed in the ${ }^{13} \mathrm{C}$ NMR spectrum at $25.7 \mathrm{ppm}$. The corresponding hydrogen atoms appear in the ${ }^{1} \mathrm{H}$ spectrum as a quintet centered at $1.99 \mathrm{ppm}$. All signal attributions were confirmed by HMQC and ${ }^{1} \mathrm{H}-{ }^{1} \mathrm{H}$ COSY analyses.

For the other moiety, proposed to be a 4-cyano1,2-dihydropyridine-type derivative, the identification was evidenced by the methylenic carbon signal observed at $46.8 \mathrm{ppm}$ in the ${ }^{13} \mathrm{C}$ NMR spectrum (C2'). The ${ }^{1} \mathrm{H}$ NMR signal at $4.01 \mathrm{ppm}$ (integration for two hydrogens) is associated with the corresponding methylenic hydrogens, as indicated by the HMQC and COSY spectra. The ${ }^{13} \mathrm{C}$ NMR signal at $115.9 \mathrm{ppm}$ is associated with the carbon of the cyano group ( $\left.\mathrm{C}^{\prime}\right)$, while the signal at $112.3 \mathrm{ppm}$ corresponds to $\mathrm{C} 4$ ' (the carbon bearing the cyano group).

The ${ }^{1} \mathrm{H}$ NMR spectrum shows a triplet of doublets of doublets at $5.74 \mathrm{ppm}$, two doublets of doublets at $4.71 \mathrm{ppm}$ and $6.10 \mathrm{ppm}$, and a doublet at $4.01 \mathrm{ppm}$ (integrating for two hydrogens). The ${ }^{1} \mathrm{H}$ NMR analyses are consistent with a similar compound described in the literature ( $N$-methyl-1,2-dihydropyridine). ${ }^{11}$

In addition to the absorption band at $336 \mathrm{~nm}$, compound 4 emits fluorescence. We experimentally observed that the 4-pyridone moiety does not show fluorescence, while 2-pyridone does, reinforcing the presence of a 2-pyridone group in the structure of $\mathbf{4}$.

The instability of compound $\mathbf{4}$ may be attributed to the 1,2-dihydropyridine portion of the molecule, which is easily oxidized. ${ }^{12,13}$ The kinetic study of $\mathbf{4}$ in water at $\mathrm{pH} 12$ monitored by UV-Vis showed a slow reaction in which the band at $336 \mathrm{~nm}$ is shifted to $315 \mathrm{~nm}$ with the simultaneous formation of a new band at $262 \mathrm{~nm}$. These products were not identified due to their low concentrations. No ring-opening products, such as glutaconaldehyde derivatives, ${ }^{13,14}$ were observed. However, at room temperature, the compound acquired a dark color, even in the solid state, which probably indicates an oxidative process. This behavior is in fact expected, considering that some $N$-methylhydropyridines, enamine derivatives, are unstable. Some enamines are susceptible to acid-catalyzed dimerization however in the absence of potassium hydroxide pellets, $\mathrm{N}$-methyl-1,2-dihydropyridine is stable to dimerization for days while $N$-methyl-1,4-dihydropyridine is stable for weeks under similar conditions. ${ }^{15}$ Decomposition can be minimized under argon at $-30{ }^{\circ} \mathrm{C} .{ }^{16}$

Finally, it is possible to speculate the mechanism that leads to 4 . Our kinetic experiments monitored by 

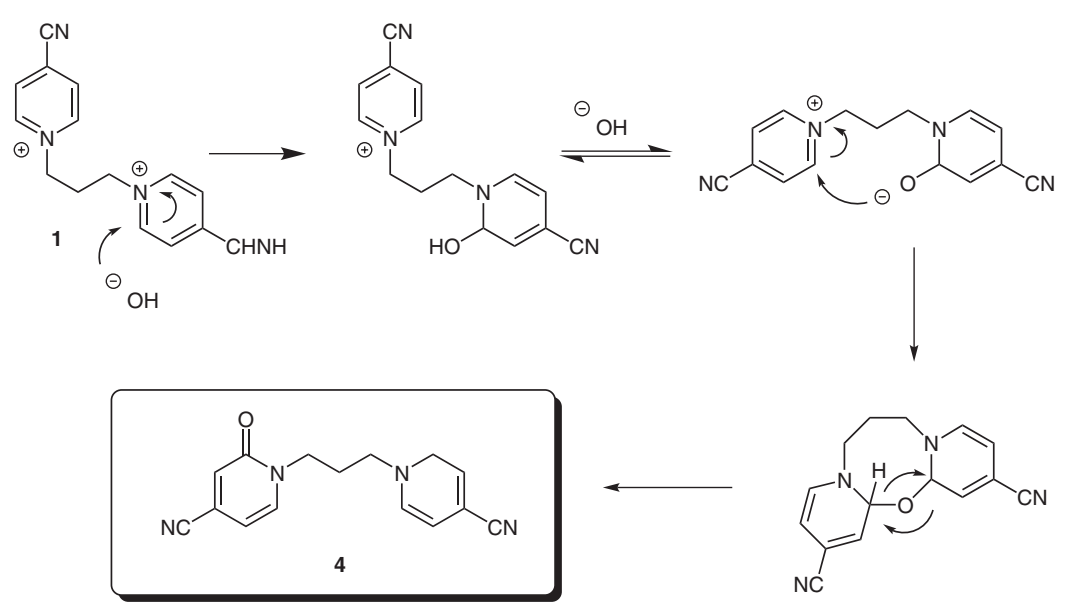

Scheme 4. Proposed mechanism for the formation of 4.

absorption and fluorescence spectrophotometries showed that the appearance of the $336 \mathrm{~nm}$ absorption band is not accompanied by immediate fluorescence emission. The $336 \mathrm{~nm}$ UV-Vis band appeared in a time scale of seconds, while the fluorescence emission was observed in a time scale from minutes to hours. However, product 4 is fluorescent. Therefore, these results indicate that a non-fluorescent intermediate is produced and consumed before $\mathbf{4}$. The reaction route of $\mathbf{1}$ with $\mathrm{OH}^{-}$usually leads to (i) pyridone, as result of the ipso attack of $\mathrm{OH}^{-}$at the ring, forming the respective pseudo base at position 4-, and (ii) carboxamidopyridinium, resulting from the nucleophilic attack of $\mathrm{OH}^{-}$in the cyano group. Therefore the intermediate should be formed by an alternative reaction route: the nucleophilic attack of $\mathrm{OH}^{-}$at $\mathrm{C} 2$ is possible due to the well-known reactivity of this position. ${ }^{17}$ The formed pseudo base at $\mathrm{C} 2$ undergoes ionization at $\mathrm{pH}$ values higher than $11.5,12,13,18$ which due to the relative proximity to the unreacted vicinal pyridinium ring may lead to a cyclic ethertype intermediate. This ether could rearrange through an intramolecular hydride shift, resulting in the product $\mathbf{4}$, as depicted in Scheme 4. The reaction intermediates before compound $\mathbf{4}$ formation can be non-fluorescent species.

Geometry minimization simulation using Gaussian 3.0 software with semi-empirical PM3 method, showed that the oxygen of the alkoxyde may approximate to the (unreacted) pyridinium ring. In addition, an unstable compound at room temperature with two pyridine rings connected by oxygen was found in the alkaline hydrolysis of 1-benzyl-3-acetylpyridinium chloride. ${ }^{13,14,19}$ This noncyclic ether is similar to compound $\mathbf{4}$. These facts suggest the conversion of the intermediate cyclic ether into $\mathbf{4}$ through an internal rearrangement. ${ }^{11,15,16}$

In the context of the present work, it is worth mentioning the results published by Günde ${ }^{20}$ involving a system closely related to ours. The author worked with bridged pyridinium salts bearing $-\mathrm{CN}$ substituents at the 3 - position (compound 5) which was observed to rearrange by intermolecular mechanism to product $\mathbf{6}$ under basic conditions, although in very low yield (Scheme 5).

However, in contrast to $\mathbf{1}$, an intramolecular process in this compound is unlikely due to the relative position of the $-\mathrm{CN}$ groups, as postulated by the author. Considering that even the compound bearing a six-atom bridge showed rearrangement, it is more plausible that an intermolecular process took place instead. This would be in agreement with all the experiments performed by our group (including those involving different concentrations of the reactant species), with derivatives $\mathbf{2}$ (six-atom bridge) and $\mathbf{3}$ (eight-atom bridge), which resulted only in non rearranged products.

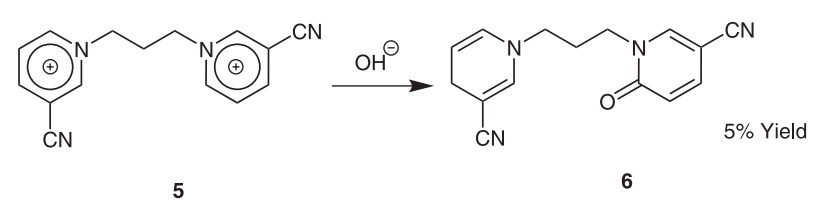

Scheme 5. As described in reference 20.

\section{Conclusions}

A new compound from the alkaline hydrolysis of pyridinium salt 1 was obtained and unambiguously identified as 1-(4-cyano-2-oxo-1,2-dihydro-1-pyridyl)-3-(4-cyano1,2-dihydro-1-pyridyl)propane (4). The generation of this product can be explained by a proximity effect of the nucleophile inserted between the two pyridinium moieties, which are not observed for the hydrolysis of derivatives 2 and $\mathbf{3}$. We previously showed the accommodation of the nucleophiles into bis(substituted-pyridinium) ions with short methylene spacers. ${ }^{8,9}$ However, the generation of $\mathbf{4}$ is related to a peculiar reactivity of the bis-(4-cyanopyridinium) compound linked by a three-methylene bridge. The formation of the cyclic ether 
from a pseudo base at $\mathrm{C} 2$ followed by a disproportionation product with intramolecular hydrogen transfer is speculated.

\section{Experimental}

\section{General procedure}

UV absorption and fluorescence determinations were performed, in a Cary-50 (Varian) and in a LS-5 (Perkin Elmer) equipment, respectively. The $\mathrm{pH}$ measurements were done in a pHmeter Meterlab pHM 240 apparatus with a glass electrode connected to a calomel reference. Elemental analysis was determined in Elemental Analyzer Perkin-Elmer 240B. NMR spectra were recorded in Mercury Plus BB (Varian), $300 \mathrm{MHz}$. IR spectra was obtained in FTIR/MB-100 (Bomen), in KBr. Mass spectra were taken with CGMS-DSQ II (Thermoeletric Corporation). The product synthesis, purification, and storage were carried out in the dark. The kinetic studies were followed by UV-Vis absorption and fluorescence emission spectrophotometry.

1-(4-Cyano-2-oxo-1,2-dihydro-1-pyridyl)-3-(4-cyano-1,2dihydro-1-pyridyl) propane (4)

A solution of $1(80.5 \mathrm{mg})$ in $0.1 \mathrm{~mL}$ of $\mathrm{H}_{2} \mathrm{O}$ was added to a mixture of $0.6 \mathrm{~mL}$ of $\mathrm{NaOH} / \mathrm{H}_{2} \mathrm{O}\left(\left[\mathrm{OH}^{-}\right]_{\text {final }} c a\right.$. $1.8 \mathrm{~mol} \mathrm{~L}^{-1}$ ) and $0.7 \mathrm{~mL}$ of $\mathrm{CHCl}_{3}$ at $2{ }^{\circ} \mathrm{C}$ (or in a mixture of $\mathrm{NaOD} / \mathrm{D}_{2} \mathrm{O} / \mathrm{CDCl}_{3}$ for NMR analysis). This heterogeneous mixture was vigorously agitated, and the organic phase was isolated in a separatory funnel, followed by quick filtration using a Pasteur pipette containing around $3 \mathrm{~mm}$ of $\mathrm{SiO}_{2}$. For NMR analysis, filtration was performed directly in the NMR tube, and the analyses were conducted at $-20{ }^{\circ} \mathrm{C}$. For all the other analyses, chloroform was evaporated under $\mathrm{N}_{2}$ flow and the dried product was immediately removed. No decomposition products were observed in the analyzed sample maintained at $-20{ }^{\circ} \mathrm{C}$ for $3 \mathrm{~h}$. In solid state or liquid solution, the compound became dark at room temperature after around 2 min. Yield ca. 33\%. Soluble in acetone, chloroform, and dichloromethane, and slightly soluble in water. Absorption band at $336 \mathrm{~nm}$ and fluorescence emission at $402 \mathrm{~nm}$ in water; $\mathrm{mp} 186-189^{\circ} \mathrm{C}$ (dec.); Elemental analysis found C, 67.3; H, 5.3; N, 22.0. Calc. for $\mathrm{C}_{15} \mathrm{H}_{14} \mathrm{~N}_{4} \mathrm{O}$; C, 67.6; H, 5.3; N, 21.0; IR (KBr) $v_{\max } / \mathrm{cm}^{-1}: 2234,2216,1660 ; \mathrm{MS}(\mathrm{m} / \mathrm{z}) 266\left(\mathrm{M}^{+}\right)$.

\section{Supplementary Information}

Supplementary data are available free of charge at http://jbcs.sbq.org.br, as PDF file.

\section{Acknowledgments}

We are grateful to Dr. Ivan P. A. Campos for invaluable discussions and comments. This research was financed by grants from CNPq, FAPESP and Fundação Araucária, Paraná.

\section{References}

1. Kosower, E. M.; Patton, J. W.; Tetrahedron 1966, 22, 2081.

2. Kosower, E. M.; Cotter, J. L.; J. Am. Chem. Soc. 1964, 86, 5552; Chandrasekaran, K.; Whitten, D. G.; J. Am. Chem. Soc. 1981, 103, 7270; Carey, J.; Case, J. R.; J. Chem. Soc. Perkin Trans. 1 1977, 2429; Kosower, E. M.; Poziomek, E. J.; J. Am. Chem. Soc. 1964, 86, 5515.

3. Bernhard, S.; The Structure and Function of Enzimes, W.A. Benjamin, Inc.: USA, 1968; Kosower, E. M.; An Introduction to Physical Organic Chemistry, John Wiley \& Sons, Inc.: USA, 1968.

4. Politi, M. J.; Chaimovich, H.; J. Phys. Org. Chem. 1991, 4, 207.

5. Hioka, N.; Chaimovich, H.; Tetrahedron Lett. 1989, 30, 1051.

6. Politi, M. J.; Cuccovia, I. M.; Chaimovich, H.; Almeida, M. L. C.; Bonilha, J. B. S.; Quina, F. H.; Tetrahedron Lett. 1978, 2 , 115; Chaimovich, H.; Bonilha, J. B. S.; Politi, M. J.; Quina, F. H.; J. Phys. Chem. 1979, 83, 1851.

7. Hioka, N.; PhD Thesis, Universidade de São Paulo, Brazil, 1992; available under request to the authors.

8. Fernandez, C.; Toscano, G. V.; Chaimovich, H.; Politi, M. J.; Hioka, N.; J. Phys. Org. Chem. 1998, 11, 25.

9. Corrêa, M. G. N.; Politi, M. J.; Hioka, N.; J. Phys. Org. Chem. 1999, 12, 837.

10. Choi, H-Y.; Yoon, S-H.; Bull. Korean Chem. Soc. 1999, $20,857$.

11. Stout, D. M.; Meyers, A. I.; Chem. Rev. 1982, 82, 223.

12. Schofield, K.; Heteroaromatic Nitrogen Compounds, Butterworths \& Co. Ltd.: England, 1967.

13. Bunting, J. W.; Adv. Heterocycl. Chem. 1979, $25,1$.

14. Moracci, F. M.; Casini, A.; Liberatore, F.; Carelli, V.; Tetrahedron Lett. 1976, 41, 37223.

15. Beeken, P.; Fowler, F. W.; J. Org. Chem. 1980, 45, 1336.

16. Fowler, F. W.; J. Org. Chem. 1972, 37, 1321.

17. Pozharskii, A. F.; Simonov, A. M.; Doron'kin, V. N.; Russ. Chem. Rev. 1978, 47, 1042.

18. Calderbank, A.; Charlton, D. F.; Farrington, J. A.; James, R.; J. Chem. Soc., Perkin Trans. 1 1972, 138.

19. Anderson, A. G.; Berkelhamer, G.; J. Org. Chem. 1958, 23, 1109.

20. Gündel, W-H.; Z. Naturforsch., B: Chem. Sci.1983, 38, 873.

Submitted: December 20, 2010

Published online: June 7, 2011 


\title{
Characterization Studies of 1-(4-Cyano-2-oxo-1,2-dihydro-1-pyridyl)-3-(4-cyano- 1,2-dihydro-1-pyridyl)propane Formed from the Reaction of Hydroxide Ion with 1,3-Bis-(4-cyano pyridinium)propane
}

\author{
Simone Fiori, ${ }^{a}$ Ivânia T. A. Schuquel, ${ }^{a}$ Idélcio N. da Silva, ${ }^{b}$ Mário J. Politi, ${ }^{c}$ \\ Luiz H. Catalani, ${ }^{c}$ Hernan Chaimovich, ${ }^{c}$ Emerson Meyer ${ }^{a}$ and Noboru Hioka ${ }^{*, a}$ \\ ${ }^{a}$ Departamento de Química, Universidade Estadual de Maringá, 87020-900 Maringá-PR, Brazil \\ ${ }^{b}$ Fundação Educacional do Município de Assis, 19807-634 Assis-SP, Brazil \\ 'Instituto de Química, Universidade de São Paulo, 05508-000 São Paulo-SP, Brazil
}

\section{Experimental}

Synthesis and characterization of reactants

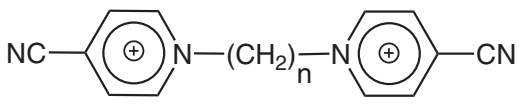
(1) $n=3$
(2) $n=6$
(3) $n=8$

The 1,3-bis(4-cyanopyridinium)propane bromide, $\mathbf{1}$, was synthesized taking $32.27 \mathrm{~g} \mathrm{(310} \mathrm{mmol)} \mathrm{of} \mathrm{4-cyanopyridine}$ and $16.15 \mathrm{~g}(80 \mathrm{mmol})$ of 1,3-dibromo propane in acetonitrile $(50 \mathrm{~mL})$. The mixture was heated under reflux and stirred for $48 \mathrm{~h}$ in the dark. The precipitated product was filtered and recrystallized in ethanol/water $(\times 3)$ yielding yellow needles. Compounds $\mathbf{2}$ and $\mathbf{3}$ were prepared in a similar way.

\section{Compound 1}

Yield $16.7 \mathrm{~g}(51 \%)$. Absorption at $278.0 \mathrm{~nm}(\varepsilon=$ $\left.8.90 \times 10^{3} \mathrm{~L} \mathrm{~mol}^{-1} \mathrm{~cm}^{-1}\right) . \mathrm{mp} 276-278^{\circ} \mathrm{C}(\mathrm{dec})\left(276-277^{\circ} \mathrm{C}\right)$. Anal. Calc. for $\mathrm{C}_{15} \mathrm{H}_{14} \mathrm{~N}_{4} \mathrm{Br}_{2}$ : C, 43.93; H, 3.44; N, 13.66; Br, 38.97. Found: C, 43.54; H, 3.50; N, 13.53; Br, 37.8. IR (KBr) $v_{\max } / \mathrm{cm}^{-1}: 2241(\mathrm{CN})$. MS $(\mathrm{m} / z) 118\left(\mathrm{C}_{7} \mathrm{H}_{6} \mathrm{~N}_{2}^{+*}\right)$, 104 (118 - $\mathrm{CH}_{2}$, base peak), 77 (104 - HCN). ${ }^{1} \mathrm{H}$ NMR (60 $\left.\mathrm{MHz}, \mathrm{D}_{2} \mathrm{O}\right) \delta(\mathrm{ppm}), 9.3(4 \mathrm{H}, \mathrm{d}), 8.6(4 \mathrm{H}, \mathrm{d}), 5.0(4 \mathrm{H}, \mathrm{t})$, $2.8(2 \mathrm{H}, \mathrm{s})$.

Characterization of 1-(4-cyano-2-oxo-1,2-dihydro1-pyridyl)-3-(4-cyano-1,2-dihydro-1-pyridyl)propane, 4, $\mathrm{C}_{15} \mathrm{H}_{14} \mathrm{~N}_{4} \mathrm{O}$, the additional product from the alkaline hydrolysis of $\mathbf{1}$ 


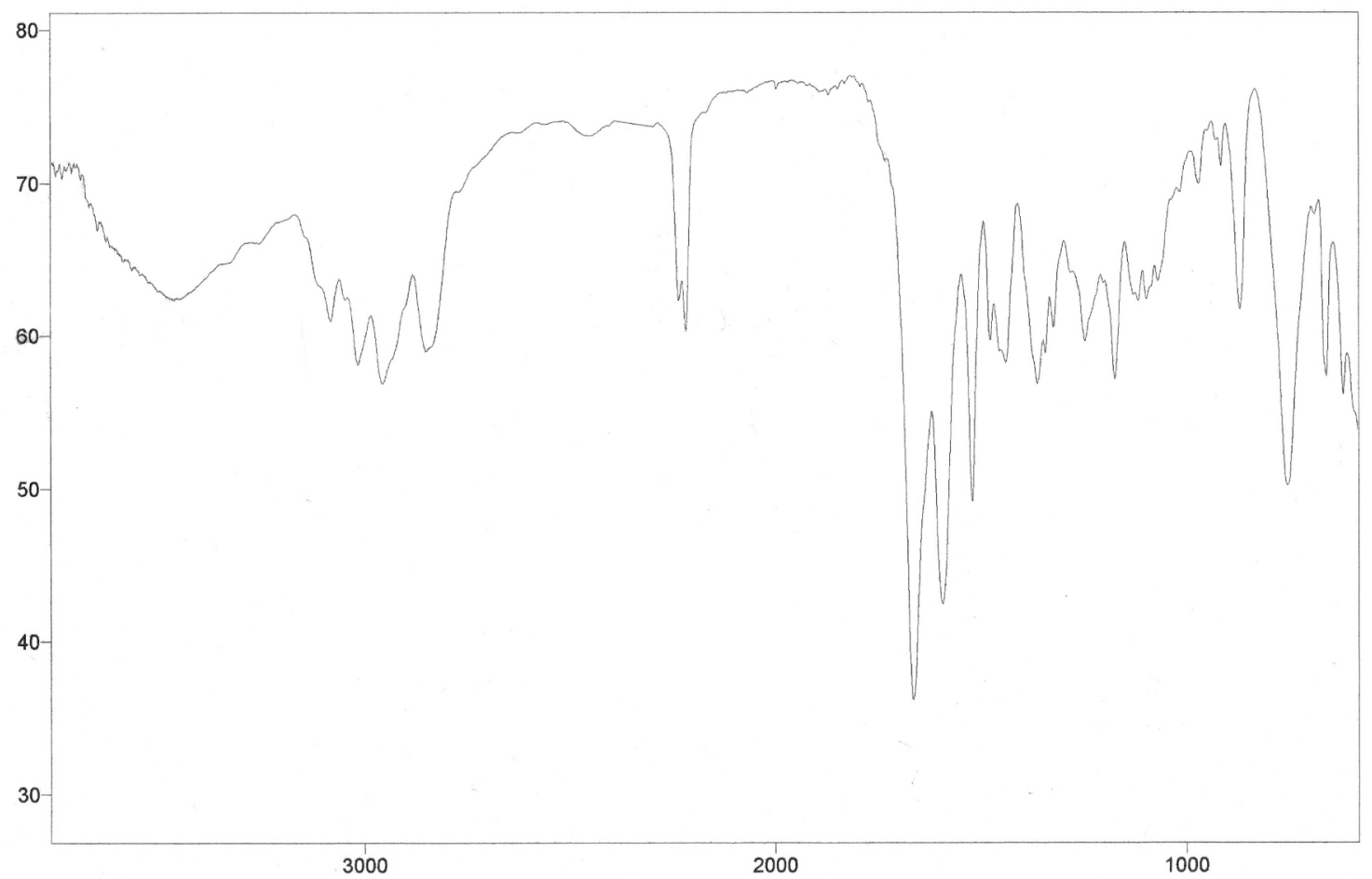

Figure S1. FTIR spectrum of the additional product 4, obtained in $\mathrm{KBr}$.
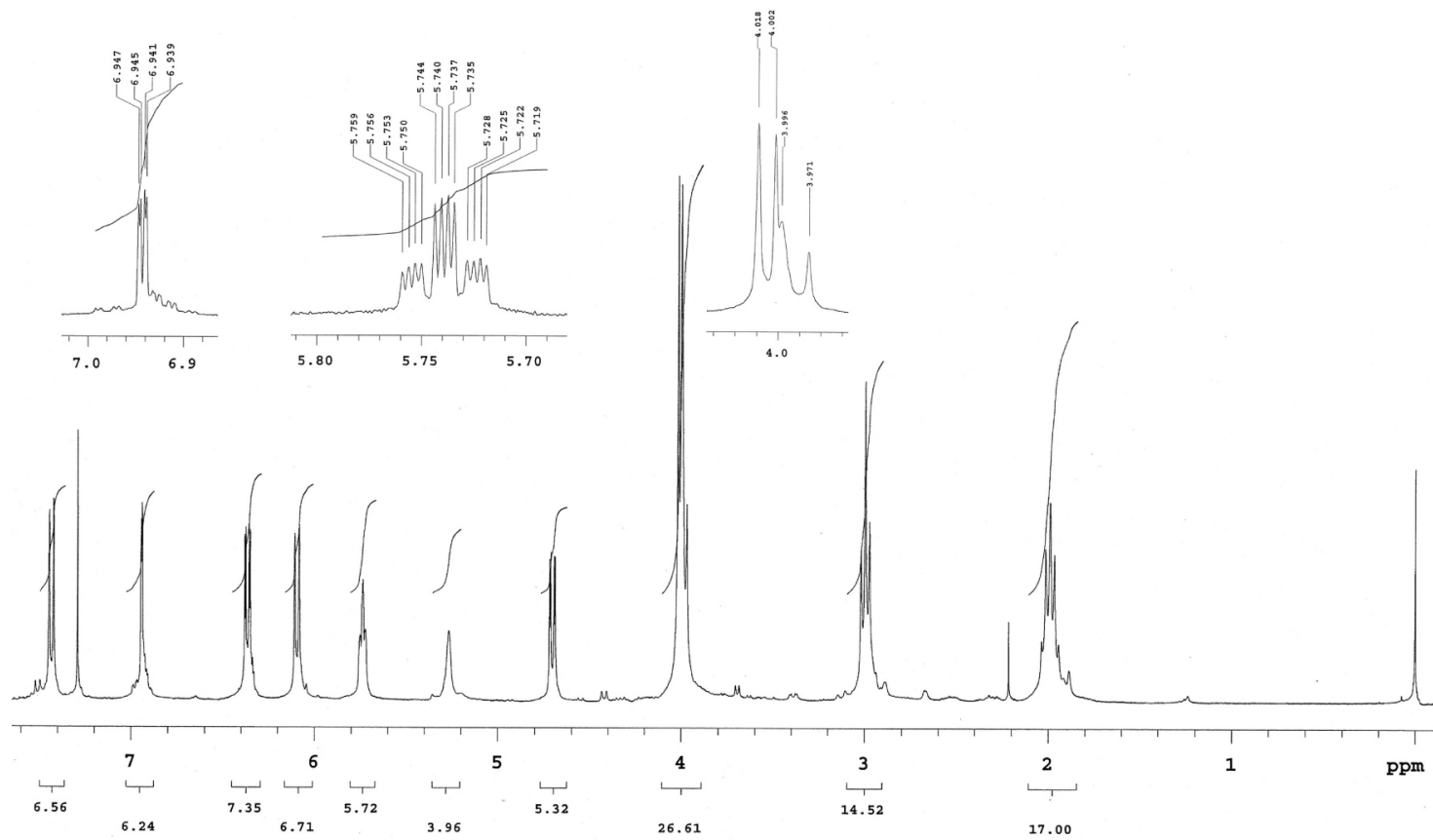

Figure S2. ${ }^{1} \mathrm{H}$ NMR spectrum of the additional product 4, measured in $\mathrm{CDCl}_{3}$ at $-20{ }^{\circ} \mathrm{C}$. 


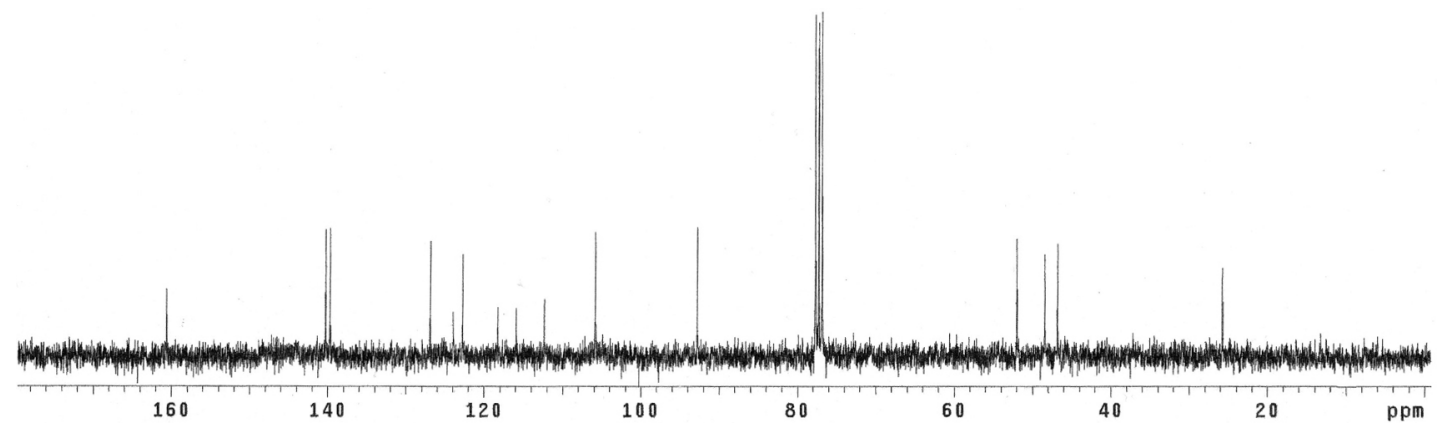

Figure S3. ${ }^{13} \mathrm{C}$ NMR spectrum of the additional product 4 , measured in $\mathrm{CDCl}_{3}$ at $-20{ }^{\circ} \mathrm{C}$.

\section{C3H-DEPT-20}

F11e. C3H-DrbT-20C. s.t1d

Dul oe sequenoe. aspt
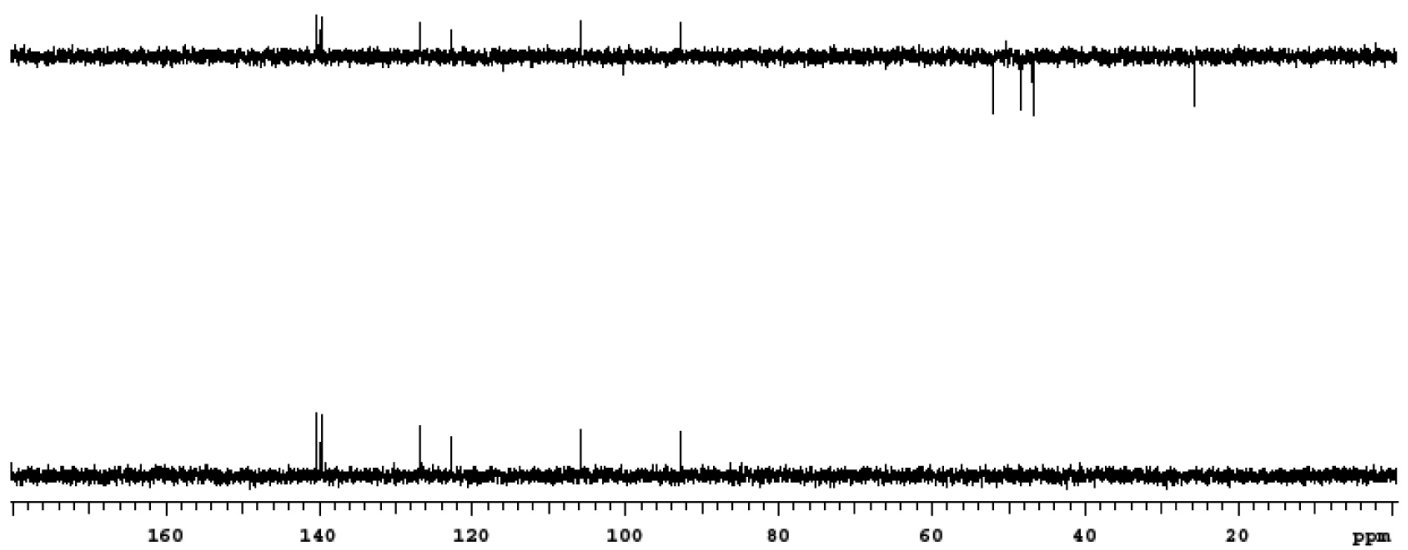

Figure S4. DEPT 90 and $135 \mathrm{NMR}$ spectra of the additional product 4, measured in $\mathrm{CDCl}_{3}$ at $-20^{\circ} \mathrm{C}$. 
c3H-cost-20c

Fi10, C3H-Cosy-20c.s.rid

Du10e sequence. cosy
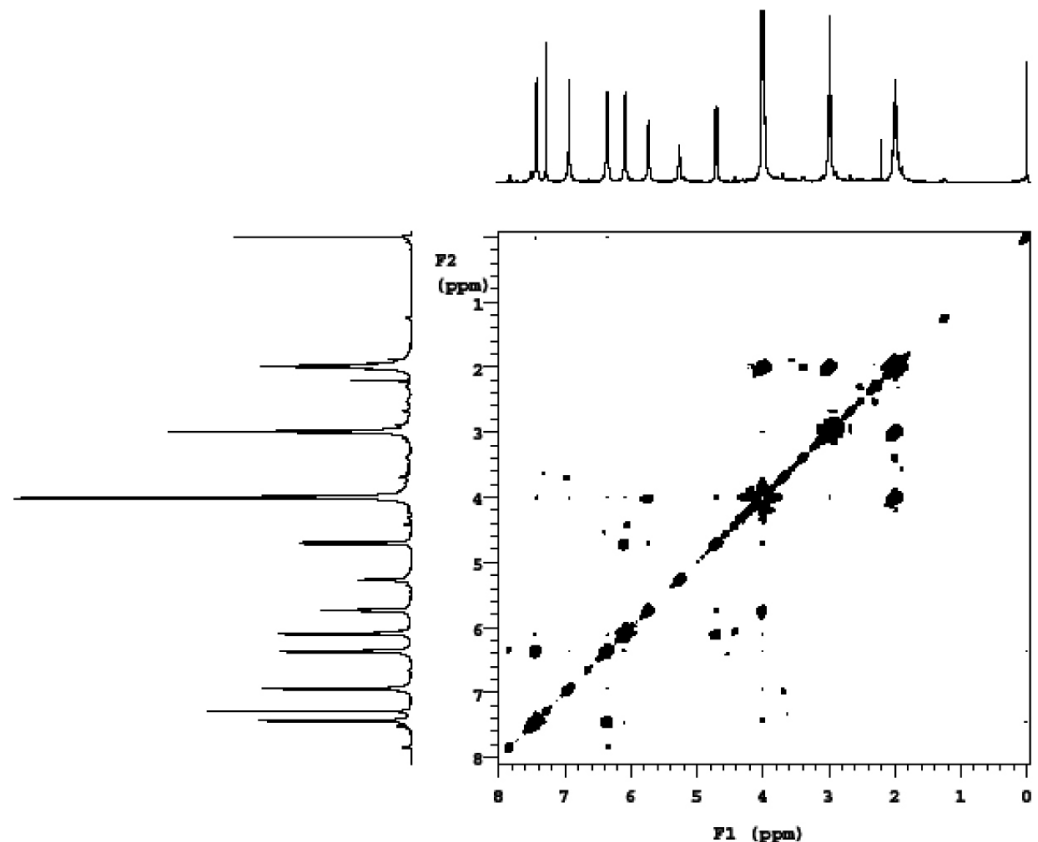

Figure S5. COSY-NMR spectrum of the additional product 4, measured in $\mathrm{CDCl}_{3}$ at $-20{ }^{\circ} \mathrm{C}$.

C3B-HHac-20C

F110. C3H-Bagc-asc.s.tid

Duloe sequencen Herge
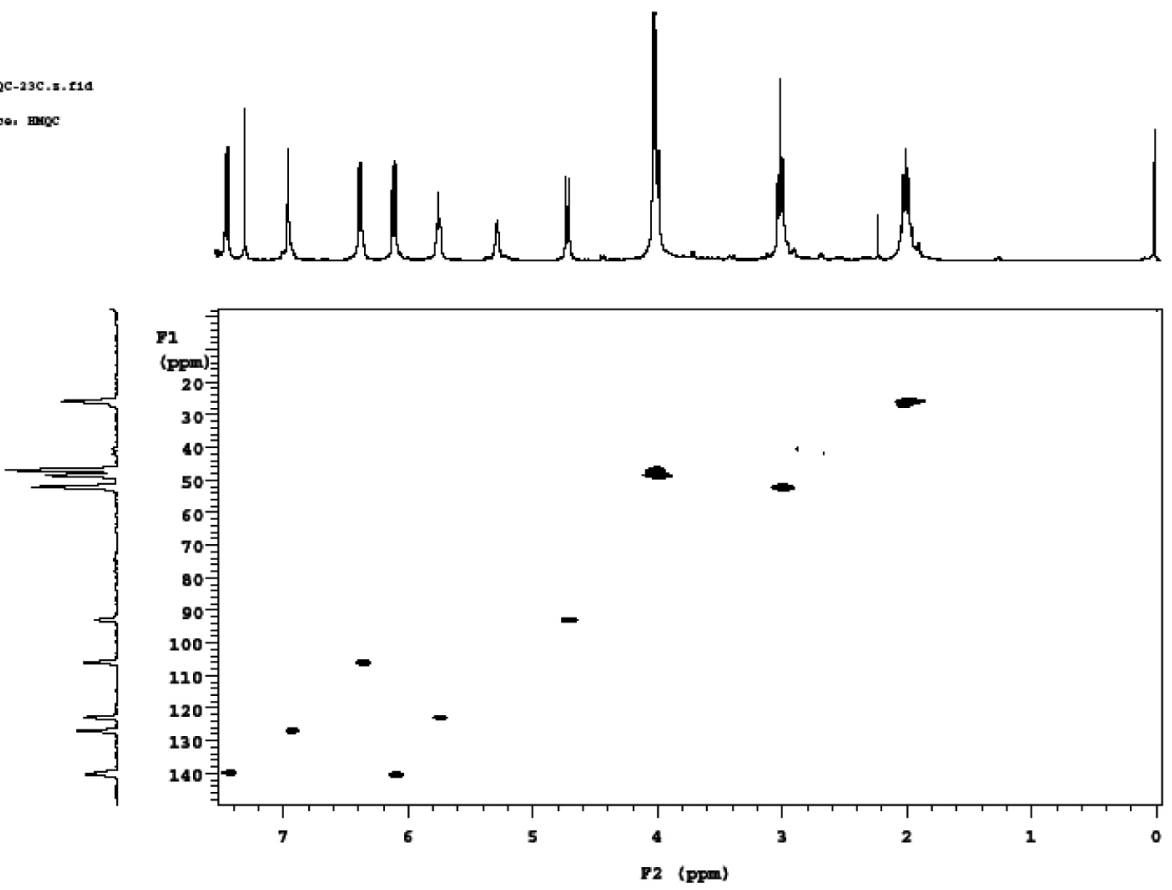

Figure S6. HMQC-NMR spectrum of the additional product 4, measured in $\mathrm{CDCl}_{3}$ at $-20^{\circ} \mathrm{C}$. 


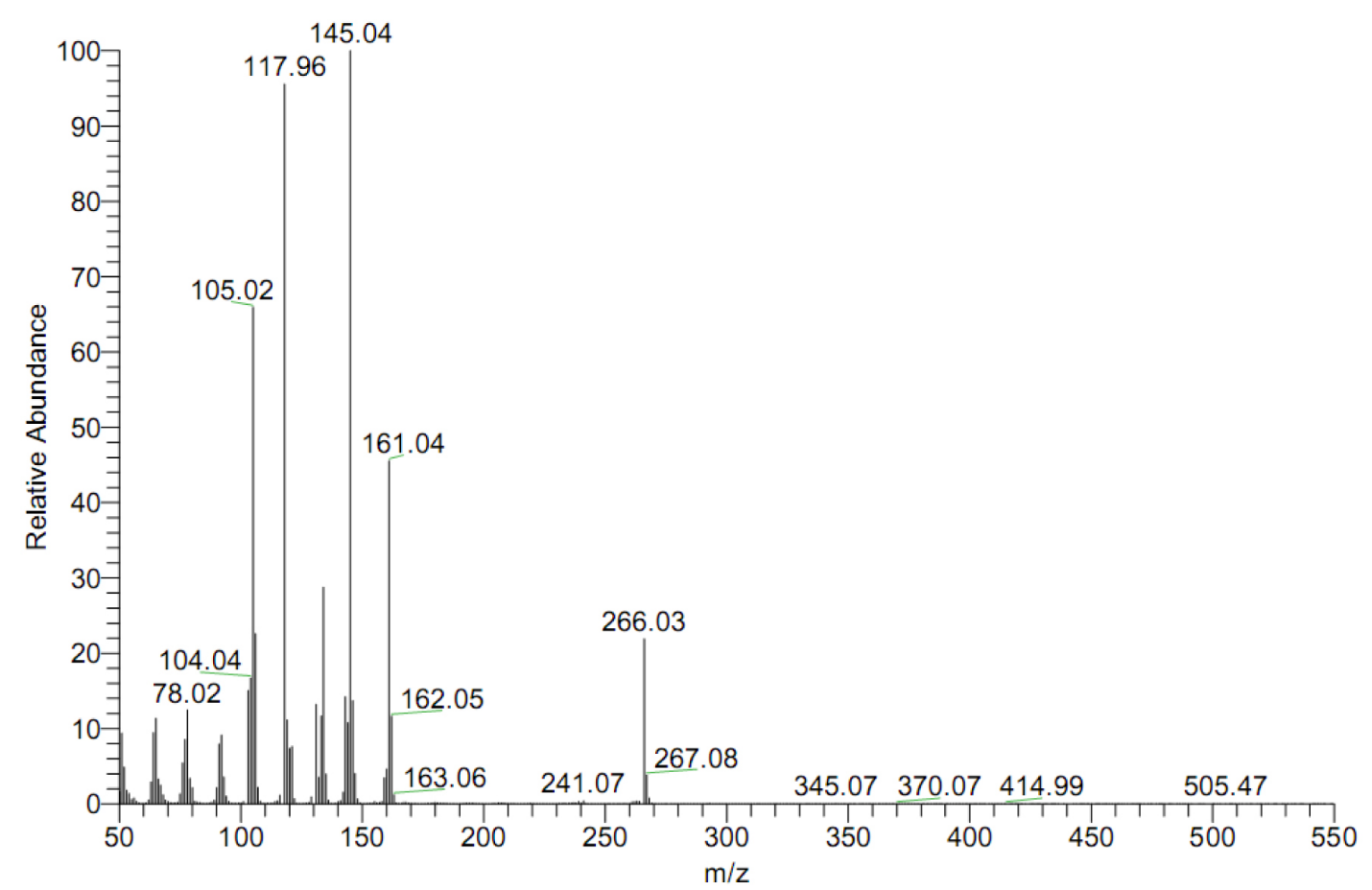

Figure S7. Mass spectrum of the additional product 4.

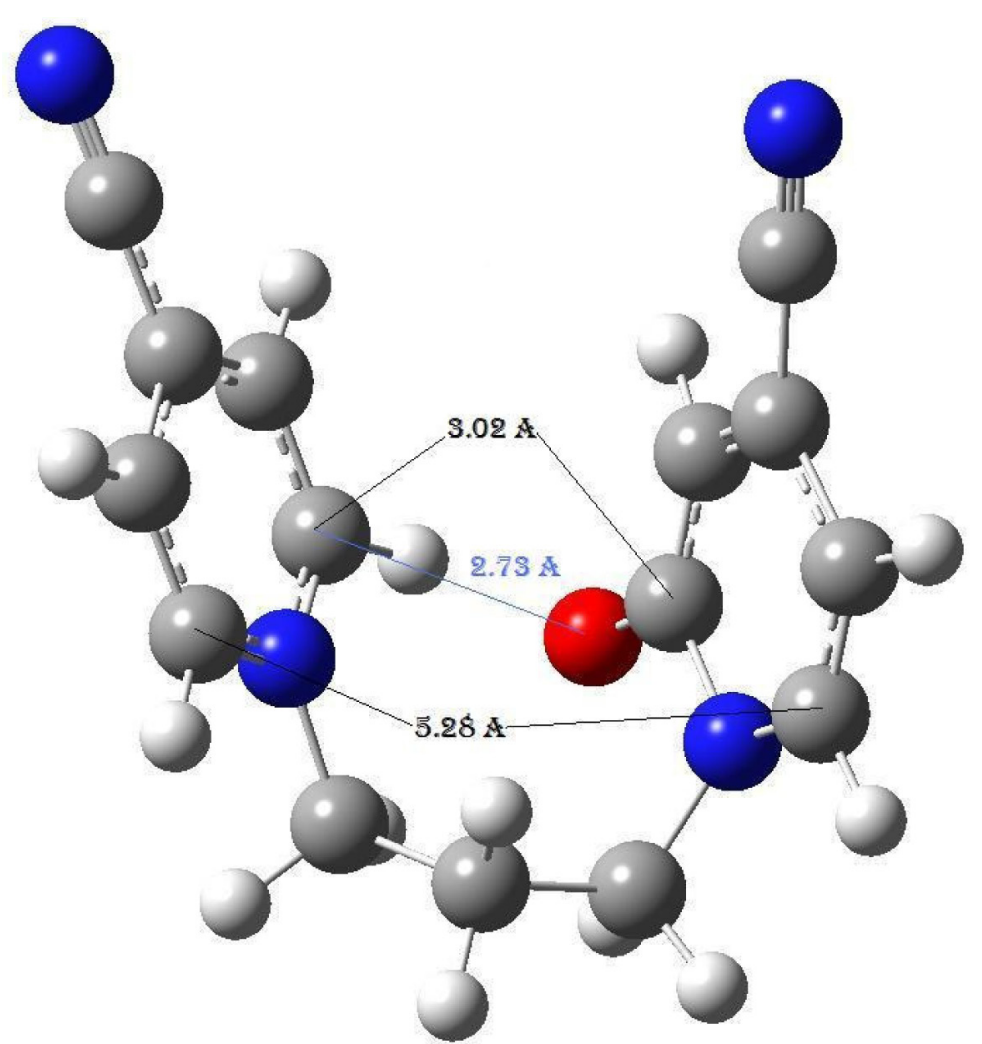

Figure S8. Geometry minimization simulation using Gaussian 3.0 software with semi-empirical PM3 method: oxygen of the alkoxyde group is directed toward to the unreacted pyridinium ring. 